\title{
UTILIZAÇÃO DE ÁCIDO 3-INDOLIL-BUTÍRICO NO ENRAIZAMENTO DE ESTACAS FOLIARES DE ROSA-DE-PEDRA (Echeveria elegans ROSE)
}

\author{
Juliana Stefanelli Carrascosa* \\ Patrícia Franco Gianini* \\ Cristiano Pedroso-de-Moraes***
}

RESUMO: O objetivo do estudo foi avaliar o enraizamento e crescimento de estacas e plântulas de Echeveria elegans submetidas a diferentes concentrações de ácido 3-indolil-butírico (AIB). Estacas foliares foram divididas em grupos de 100 unidades que foram imersas em soluções de 0, 50, 100 e 200 ppm de AIB, por período de 30 minutos. Cada grupo de estacas foi subdividido em quatro caixas gerbox transparentes contendo vermiculita umedecida, perfazendo um total de 25 estacas cada. As caixas foram fechadas e mantidas durante 60 dias em B.O.D., à temperatura de 25 ${ }^{\circ} \mathrm{C}$, sob fotoperíodo de 12 horas e intensidade luminosa de aproximadamente 116 $\mu \mathrm{mol} . \mathrm{m}^{-2} . \mathrm{s}^{-1}$. A concentração de $100 \mathrm{ppm}$ de AIB utilizada foi a que obteve os melhores resultados para as variáveis analisadas: número de raízes (NR), número de folhas (NF), diâmetro caulinar (EC), comprimento da maior raiz (CMR), comprimento da maior folha (CMF), matéria fresca total (MFT) e matéria seca total (MST). A concentração de 200 ppm apresentou efeito fitotóxico para as estacas foliares.

PALAVRAS-CHAVE: Crassulaceae; Produção Vegetal; Propagação Vegetativa.

\section{INDOLE-3-BUT YRIC ACID IN THE ROOTING OF PLANTING STOCK OF Echeveria elegans ROSE (ROSA-DE-PEDRA)}

ABSTRACT: Rooting and growth of planting stock and seedlings of Echeveria elegans at different concentrations of índole-3-butyric acid (AIB) are evaluated. Foliar planting stock was divided into 100 units immersed in 0, 50, 100 and $200 \mathrm{ppm}$ of AIB solution for 30 minutes. Each planting stock was subdivided into four transparent gerbox boxes with wet vermiculite totaling 25 planting stocks. The boxes were

\footnotetext{
Especialização em andamento em Biotecnologia pelo Centro Universitário Herminio Ometto de Araras, (UNIARARAS), Brasil.

** Bióloga pelo Centro Universitário Herminio Ometto de Araras, (UNIARARAS), Brasil

${ }^{* * *}$ Docente Doutor em Biologia Vegetal; Docente no Centro Universitário Hermínio Ometto (UNIARARAS), Araras, (SP), Brasil; E-mail: pedroso@uniararas.br
} 
closed and maintained in BOD for 60 days at $25^{\circ} \mathrm{C}$, under a 12-h photoperiod and approximately $116 \mu \mathrm{mol} . \mathrm{m}^{-2} \cdot \mathrm{s}^{-1}$ light intensity. The concentration of $100 \mathrm{ppm}$ of AIB had the best results for the analyzed variables: number of roots (NR), number of leaves $(\mathrm{NF})$, stem diameter $(\mathrm{EC})$, length of the longest root (CMR), length of the largest leaf (CMF), total fresh matter (MFT) and total dry matter (MST). Concentration of $200 \mathrm{ppm}$ had phytotoxic effect on the leaf planting stock.

KEY WORDS: Crassulaceae; Vegetal Production; Vegetative Propagation.

\section{INTRODUÇÃO}

Nativa do México e pertencente à família Crassulaceae, Echeveria elegans Rose, conhecida popularmente como Rosa-de-Pedra ou Bola-de-Neve-Mexicana, caracteriza-se como espécie herbácea, perene, suculenta, heliófila, com dimensões de 15 a $20 \mathrm{~cm}$ de altura, e 5 a $20 \mathrm{~cm}$ de diâmetro (LORENZI, 2008; ASSOCIAÇÃO MUNDIAL DE HORTICULTURA, 2011). Tal planta apresenta-se euribionte em relação à temperatura, desenvolvendo-se rapidamente quando submetida a cultivo a pleno sol em substratos ricos em matéria orgânica e com excelente drenagem (WILLINS, 2006). Esta apresenta folhas em rosetas de coloração verde-azulada, espessas e cerosas, o que confere exoticidade ao vegetal, que culmina em seu amplo interesse horticultural ornamental. Suas inflorescências racemosas apresentam flores róseas que surgem no verão. Embora possa ser multiplicada por sementes, sua propagação é feita pelo emprego, principalmente, de estacas foliares (LORENZI, 2008). Mudas de E. elegans são comercializadas no Estado de São Paulo, Brasil, em média, por R\$ 5,00, apresentando, portanto, apelo atacadista. Dessa forma, visando-se a obtenção de maior produtividade, faz-se necessária a melhoria das técnicas de propagação da espécie.

Para acompanhar a demanda do mercado, produtores de plantas ornamentais têm investido e utilizado tecnologias para melhoria de suas condições de cultivo, como estufas com controle de umidade, temperatura, irrigação, adubação, iluminação e técnicas que permitam a obtenção de mudas de maior qualidade em menor tempo como, por exemplo, o uso de reguladores de crescimento e substâncias promotoras de enraizamento (PEDROSO-DE-MORAES, 2000). Nesse ínterim, a propa- 
gação de espécies pelo método de estaquia apresenta-se rápida e, muitas vezes, mais rentável que a via seminal.

Estacas podem ser obtidas de diferentes segmentos do corpo vegetal, com muitas espécies podendo ser propagadas por um ou mais tipos de propágulos. A seleção do tipo de estaca, portanto, ocorre de acordo com a disponibilidade de material vegetativo e a facilidade de sua obtenção. É válido ressaltar que esta via de propagação tona-se possível devido à capacidade que certos órgãos vegetais apresentam de se regenerar quando excisados e acondicionados favoravelmente, dando origem a novos indivíduos com características idênticas às do genitor (SHIMADA et al., 2006). Ainda, com relação à utilização de estacas foliares, estas apresentam maior efetividade em capturar os ganhos genéticos obtidos por programas de melhoramento.

São relatados na literatura estudos sobre propagação a partir da estaquia foliar influenciadas, ou não, pelo uso de auxinas (McNEILAN; LAGERSTEDT, 1967), podendo ser citados como exemplos os realizados para Begonia (SHIMADA et al., 2006), o de Saintpaulia ionantha H. Wendl. (LOPES et al., 2005) e Psychotria viridis Ruiz \& Pavon (SALGADO et al., 2012).

O potencial de enraizamento, bem como a qualidade e a quantidade das raízes em estacas, podem variar com a espécie, o cultivar, as condições ambientais e as condições internas da planta (HARTMANN et al., 2002). Reservas mais abundantes em tecidos vegetais, principalmente, maiores disponibilidades de carboidratos, correlacionam-se com maiores porcentagens de enraizamento e de sobrevivência das estacas, pois o uso de auxinas para estimular um maior e mais rápido desenvolvimento do sistema radicial requer fonte de carbono para a biossíntese de ácidos nucleicos e de proteínas para a formação de raízes (FACHINELLO et al., 1995).

Assim, o presente trabalho teve por objetivo avaliar o enraizamento e posterior crescimento de plântulas de E. elegans influenciada por diferentes concentrações de ácido 3-indolil-butírico (AIB). 


\section{MATERIAL E MÉTODOS}

O experimento foi realizado de maio a agosto de 2013 no Laboratório de Análises Ambientais do Centro Universitário Hermínio Ometto - Uniararas. Para sua realização foram obtidas 400 estacas foliares de plantas maturas e em perfeito estado fitossanitário de Echeveria elegans oriundas do viveiro de mudas institucional.

O procedimento teve início com a separação das folhas, cujo critério de seleção foi visual. Foram utilizados como padrão a altura e peso aproximados a fim de se obter menor desuniformidade de estande e proporcionar a cada estaca a mesma condição inicial de propagação (JUNGHANS; SOUZA, 2009). Após a coleta das estacas foliares, realizaram-se tanto a pesagem das mesmas com balança de precisão analítica (Gehaka BG 400) como a medição da altura com o paquímetro digital (Digimess 100A). A média das pesagens das estacas foi de $1,43 \mathrm{~g}$ e das alturas em torno de $4,2 \mathrm{~cm}$, com variação de $3 \mathrm{~mm}$ para mais ou para menos.

As estacas foram divididas em grupos de 100 unidades, que posteriormente foram imersas em $50 \mathrm{~mL}$ de soluções de 0, 50, 100 e 200 ppm de AIB, por um período de 30 minutos. Cada grupo de estacas foi subdividido em quatro caixas gerbox transparentes contendo $500 \mathrm{~g}$ de vermiculita umedecida com $150 \mathrm{~mL}$ de água destilada, perfazendo um total de 25 estacas cada. As caixas gerbox foram fechadas e mantidas durante 60 dias em câmara climática (B.O.D. MA 403), à temperatura constante de $25^{\circ} \mathrm{C}$, sob fotoperíodo de 12 horas e intensidade luminosa de aproximadamente $116 \mu \mathrm{mol} . \mathrm{m}^{-2} . \mathrm{s}^{-1}$ (DEZAN et al., 2012).

Ao final do experimento, para cada plântula obtida por estaca, foram avaliados: número de raízes (NR) e folhas da roseta (NF). Também foi auferido por meio de paquímetro digital (Digimess 100A), o diâmetro caulinar (EC), comprimento da maior raiz (CMR) e maior folha (CMF). A matéria fresca total (MFT) e a matéria seca total (MST), esta última determinada colocando-se o material em temperatura de $65{ }^{\circ} \mathrm{C}$ até atingir a massa seca constate, foram obtidas pelo uso de balança analítica (Gehaka BG 400) (PEDROSO-DE-MORAES et al., 2009a; 2009b; CUNHA et al., 2011; DEZAN et al., 2012).

Os resultados foram submetidos à análise de regressão polinomial utilizando-se o aplicativo estatístico BioEstat 5.3 (AYRES et al., 2007). Para escolha do 
modelo de regressão que melhor se ajustasse aos dados observados levou-se em consideração o fato de o desvio da regressão ser não significativo e o modelo de maior ordem apresentar grau significativo e, por último, o valor do coeficiente de determinação ( $\left.\mathrm{R}^{2}\right)$ (FERNANDES et al., 2012).

\section{RESULTADOS E DISCUSSÃO}

Pode-se auferir que a concentração de 200 ppm apresentou efeito fitotóxico nas estacas foliares de Echeveria elegans, pois foi a responsável pela obtenção dos piores resultados para todas as variáveis analisadas: número de raízes (NR), número de folhas (NF), espessura do caulinar (EC), comprimento da maior raiz (CMR), comprimento da maior folha (CMF), matéria fresca total (MFT) e matéria seca total (MST) (Figuras 1 e 2).

Os resultados obtidos nas regressões polinomiais demonstram que a concentração de 100 ppm de AIB utilizada nas estacas foi a que obteve os melhores resultados para as variáveis supracitadas analisadas (Figuras 1 e 2). Com relação à maior rizogênese obtida nesta concentração $\left(R^{2}=0,9507, p<0,05\right)$, sabe-se que, de modo geral, condições endógenas dos vegetais podem ser traduzidas pelo balanço hormonal entre inibidores, promotores e cofatores que interferem no crescimento de raízes (SANTOS, 1994), sendo que quando o balanço hormonal é favorável aos promotores, ocorre o processo de iniciação radicial. 

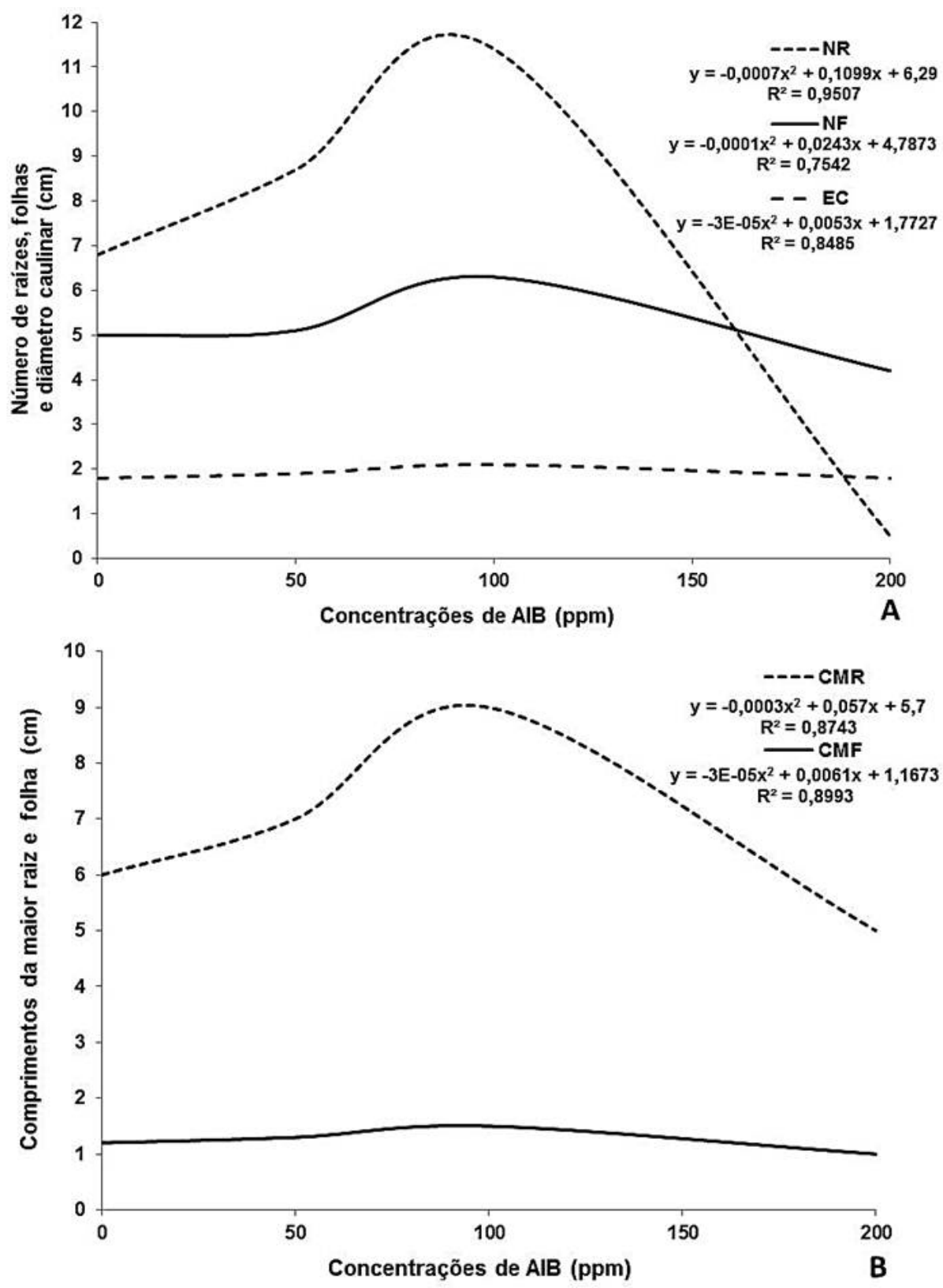

Figura 1. Características fitotécnicas de plântulas obtidas de estacas caulinares de Echeveria elegans Rose, influenciadas por diferentes concentrações de $\mathrm{AIB}$. $\mathrm{NR}=$ número de raízes; $\mathrm{NF}=$ número de folhas; $\mathrm{EC}=$ espessura caulinar (A); $\mathrm{CMR}=$ comprimento da maior raiz; $\mathrm{CMF}=$ comprimento da maior folha (B). 
A aplicação exógena de reguladores de crescimento é uma das formas mais comuns de favorecer o balanço hormonal, por elevar o teor de auxinas nos tecidos (NORBERTO et al., 2001). Ainda, como o ocorrido neste trabalho, é valido ressaltar que os meristemas axilares possuem potencial semelhante ao meristema caulinar primário, podendo formar um caule secundário se influenciado por fatores abióticos, tais como intensidade e qualidade da luz e concentrações de nutrientes disponíveis (SNOWDEN; NAPOLI, 2003; PEDROSO-DE-MORAES et al., 2011) e endógenos, sendo que as auxinas (como AIA e AIB) e citocininas estão intimamente relacionadas com a manutenção da dormência ou liberação das gemas a partir dos meristemas dos caules (CRUZ, 2009).

O conhecimento de que o tratamento de estacas com auxina estimula a formação de raízes é antigo, mas, embora tal classe de reguladores vegetais tenha sido correlacionada originalmente ao crescimento, estas substâncias químicas influenciam praticamente todos os estágios do ciclo de vida de um vegetal, da organogênese à senescência (TAIZ; ZEIGER, 2009), fato este demonstrado, neste trabalho, pelos melhores resultados obtidos para o número de folhas $(\mathrm{NF})\left(\mathrm{R}^{2}=0,7542, \mathrm{p}\right.$ $<0,05)$ e diâmetro caulinar (EC) $\left(\mathrm{R}^{2}=0,8485, \mathrm{p}<0,05\right)$ (Figura 1A) pelo uso da concentração de $100 \mathrm{mg} . \mathrm{L}^{-1}$ de AIB, e corroboradas pelos dados encontrados para Dendrobium nobile Lindl., para o qual a mesma concentração, da também auxina de estrutura química semelhante, AIA, favoreceu a maior gênese caulinar (formação de brotos axilares) e foliar (PEDROSO-DE-MORAES et al., 2011).

Com relação às estacas foliares de $E$. elegans, como característica intrínseca da planta, está o fato de que suas folhas quando destacadas do caule preservam parte ou totalidade da gema axilar aderida à base do limbo foliar, permitindo, assim, o postulado de que as folhas escolhidas para a estaquia estimularam o crescimento das raízes adventícias, pois neste caso a auxina endógena e o regulador AIB na concentração de $100 \mathrm{mg} \cdot \mathrm{L}^{-1}$, sinergisticamente, translocaram-se para a parte inferior da planta, acumulando-se na base do corte do limbo foliar, em conjunto com açúcares e outras substâncias nutritivas que permitiram a rizogênese (ALVARENGA; CARVALHO, 1983; HARTMANN et al., 1997), como demonstrado pelos dados obtidos para as variáveis número de raízes (NR) (Figura 1A), comprimento da maior raiz (CMR) $\left(\mathrm{R}^{2}=0,8743, \mathrm{p}<0,05\right)$ e comprimento da maior folha (CMF) $\left(\mathrm{R}^{2}=0,8993, \mathrm{p}<\right.$ 
0,05) (Figura 1B), também corroboradas pelo fato de que a utilização de auxinas reguladoras de crescimento tem por finalidade acelerar a emissão de raízes, número e qualidade das raízes formadas, propiciando uniformidade de enraizamento (FACHINELLO et al., 1994). Também para $D$. nobile a mesma concentração de AIA causou os maiores incrementos para as mesmas variáveis analisadas (PEDROSO-DEMORAES et al., 2011).

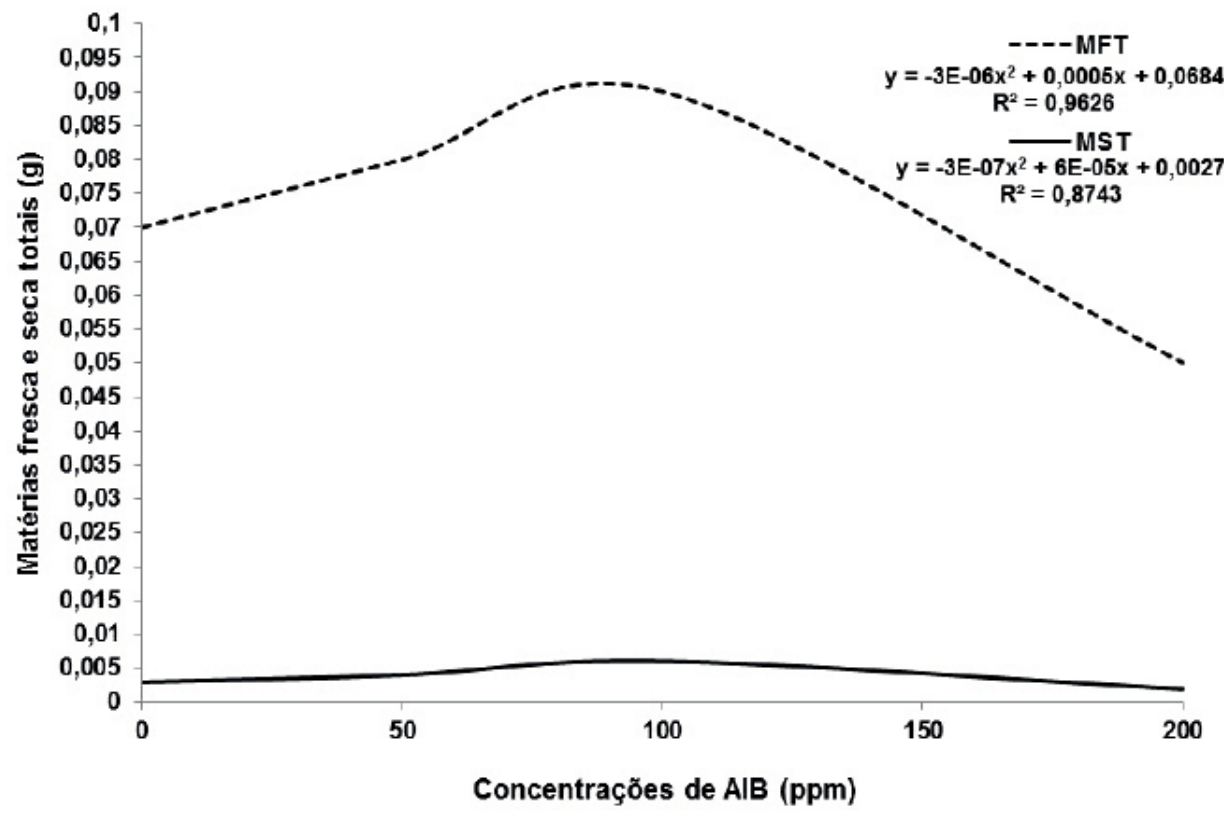

Figura 2. Características fitotécnicas de plântulas obtidas de estacas caulinares de Echeveria elegans Rose, influenciadas por diferentes concentrações de AIB. MFT $=$ massa fresca total; MST $=$ massa fresca total.

Com relação às variáveis: matéria fresca total (MFT) e matéria seca total (MST) (Figura 2), os resultados obtidos estão de acordo com a afirmação de que os diferentes processos de crescimento e desenvolvimento que ocorrem ao mesmo tempo em uma planta estão intrinsecamente relacionados, podendo o desenvolvimento de uma parte afetar de forma positiva ou negativa a de outra (CUZZUOL et al., 1996). Tal comportamento é bem evidenciado durante a formação de sistemas radiciais, para os quais o crescimento acelerado das raízes pode afetar negativamente, ou até mesmo inibir o desenvolvimento caulinar e foliar. Esta relação se deve ao 
fato de que o crescimento ativo do sistema radicial necessita de substâncias orgânicas translocadas do ápice para a base, comprometendo assim o desenvolvimento do caule e das folhas, podendo implicar no aumento de peso da matéria fresca e seca do sistema radicial (PEDROSO-DE-MORAES et al., 2011).

\section{CONSIDERAÇÕES FINAIS}

A concentração de 100 ppm de AIB utilizada nas estacas foliares de Echeveria elegans foi a que obteve os melhores resultados para todas as variáveis analisadas. A concentração de 200 ppm apresentou efeito fitotóxico para as estacas foliares da espécie.

\section{REFERÊNCIAS}

ALVARENGA, L. R.; CARVALHO, V. D. Uso de substâncias promotoras de enraizamento de estacas frutíferas. Informe Agropecuário, v. 9, p. 47-59, 1983.

ASSOCIAÇÃO MUNDIAL DE HORTICULTURA. RHS Good Plant Guide. Traducción: Gutierrez, Margarita. Dorling Limited. Barcelona, 2011, 704p.

AYRES, M.; AYRES, J. R. M.; AYRES, D. L.; SANTOS, A. S. BioEstat 5.3: aplicações estatísticas nas áreas das ciências biológicas e médicas. Belém: Sociedade Civil Mamirauá; Brasília: CNPq, 2007. 290p.

CUNHA, T.; CORDEIRO, G. M.; MASSARO, R.; DEZAN, L. F.; PEDROSO-DE-MORAES, C. Desenvolvimento in vitro de Laeliocattleya schilleriana Rolfe utilizando meios de cultivo simplificados. Scientia Plena, v. 7, p. 1-5, 2011.

CRUZ, A. B. Aspectos relacionados à competência organogenética de meristemas caulinares de Dendrobium Second Love (Orchidaceae). 2009. Tese (Doutorado) - Universidade de São Paulo, São Paulo.

DEZAN, L. F.; CANASSA, F.; SOUZA-LEAL, T.; DIOGO, J. A.; MASSARO, R.; CORDEIRO, G. M.; PEDROSO-DE-MORAES, C. Crescimento in vitro de Schomburgkia gloriosa 
Lindl. em meio de cultivo simplificados. Idesia, v. 30, p. 53-58, 2012.

FACHINELLO, J. C.; HOFFMANN, A.; NACHTIGAL, J. C.; KERSTEN, E.; FORTES, G. R. L. Propagação de plantas frutíferas de clima temperado. Pelotas: Editora e Gráfica UFPEL, 1994. 179p.

FERNANDES, M. R.; BARBOZA, M. P.; SOUZA-LEAL, T.; PEDROSO-DE-MORAES, C. Morfobiometria carpo seminal e germinação de Lafoensia pacari A. St. Hil. (Lythraceae) exposta a diferentes concentrações de GA. Semina: Ciências Agrárias, Londrina, v. 33, suplemento 1, p. 2571-2584, 2012.

HARTMANN, H. T.; KESTER, D. E.; DAVIES, F. T.; GENEVE, R. L. Plant propagation: principles and practices. 6. ed. Prentice Hall, Upper Saddle River, NJ. 1997. 757p.

JUNGHANS, T. G.; SOUZA, A. S. da. Aspectos práticos da micropropagação de plantas. Cruz das Almas: Embrapa mandioca, fruticultura e plantas tropicais. 2009. $227 \mathrm{p}$.

LOPES, J. C.; CAPUCHO, M. T.; COELHO, R. I.; SCANDIAN, A. S. R. Enraizamento de estacas foliares de violeta-africana (Saintpaulia ionantha Wendl.) em diferentes substratos. Ciência e Agrotecnologia, v. 29, p. 305-314, 2005.

LORENZI, H. Plantas ornamentais do Brasil: arbustivas, herbáceas e trepadeiras. 4. ed. Ipisis, p. 200, 2008.

MCNEILAN, R. A.; LAGERSTEDT, H. B. Plant propagation by leaf and leaf-bud cuttings. Fact Sheets, p. 115-116, 1967.

NORBERTO, P. M.; CHALFUN, N. N. J.; PASQUAL, M.; VEIGA, R. D.; PEREIRA, G. E.; MOTA, J. H. Efeito da época de estaquia e do AIB no enraizamento de estacas de figueira (Ficus carica L.). Ciência e Agrotecnologia, v. 25, p. 533-541, 2001.

PEDROSO-DE-MORAES, C. Cultivo de orquídeas. Araras: Biblioteca Duse Rüegger Ometto, 2000. 130p.

PEDROSO DE MORAES, C.; DIOGO, J. A.; PEDRO, N. P.; CANABRAVA, R. I.; MARTINI, G. A.; MARTELINE, M. A. Desenvolvimento in vitro de Cattleya loddigesii Lindley (Orchidaceae) utilizando fertilizantes comerciais. Revista Brasileira de Biociências, v. 7, p. 67-69, 2009. 
PEDROSO-DE-MORAES, C.; SANTOS, N. S.; MASSARO, R.; CORDEIRO, G. M.; SOUZA-LEAL, T. Desenvolvimento in vitro de Cattleya tigrina A. Richard. (Orchidaceae) utilizando fertilizantes comerciais. Ensaios e Ciência, v. 13, p. 57-65, 2009.

PEDROSO-DE-MORAES, C.; SOUZA-LEAL, T.; PEDRO, N. P.; MARTINI, G. A.; MORO, A. M. AIA no estímulo de brotos laterais em estacas de Dendrobium nobile Lindley (Orchidaceae). Ensaios e Ciência, v. 15, p. 111-119, 2011.

SALGADO, M. P. G.; FURLAN, R. M.; AOYAMA, E. M.; RODRIGUES, E.; CRUZ, L. P. Propagação assexuada de Chacrona (Psychotria viridis Ruiz \& Pavon) via estaquia foliar. Revista em Agronegócios e Meio Ambiente, v. 5, p. 383-396, 2012.

SANTOS, P. E. T. dos. O uso da clonagem na silvicultura intensa. Revista Silvicultura, v. 15 , p. $28-30,1994$.

SHIMADA, Y.; MORI, G.; KATAHARA, Y.; ODA, M. Formation of adventitious buds on leaf pieces cutting of Begonia Tuber hybrida group. Journal of Japanese Society of Horticultural Science, v. 75, p. 318-322, 2006.

SNOWDEN, K. C.; NAPOLI, C. A. A quantitative study of lateral branching in petunia. Functional Plant Biology, v. 30, p. 987-994, 2003.

TAIZ, L.; ZEIGER, E. Fisiologia vegetal. 4. ed. Porto Alegre: Artmed, 2009, p. 449484 .

Recebido em: 10 de abril de 2014 Aceito em: 02 de outubro de 2014 